\title{
Estimation of serum prostaglandin D2 levels and its expression in tissue of Alopecia areata
}

\author{
Talal A. Abd-ElRaheem1, Samar M.R. El-Tahlawy2, Olfat G. Shaker3, Mohamed \\ H.Mohamed4 and Yasmin F.Soliman5
}

1. M.D, professor of Dermatology, STDs and Andrology department, Faculty of Medicine Fayoum University.

2. M.D, professor of Dermatology department, Faculty of Medicine Cairo University

3. M.D, professor of Biochemistry department, Faculty of Medicine-Cairo University

4. MD, lecturer of Dermatology, STDs and Andrology department, Faculty of Medicine Fayoum University

5. M.B.B.CH, Dermatology, STDs and Andrology department, Faculty of Medicine, Cairo University

\begin{abstract}
$\underline{\text { Abstract }}$
Back ground: Alopecia areata is a recurrent, non-scaring type of hair loss considered to be an autoimmune process. Though its etiopathogenesis is not fully understood, many therapeutic options have been used by dermatologists, but none are curative or preventive. Prostaglandins analogues which are used to treat glaucoma. Increase in eye lash number, thickness and pigmentation have been reported as side effect.
\end{abstract}

Methods: This cross sectional case control study was conducted on thirty seven Egyptian patients with alopecia areata including 15 females and 22 males with age ranging from 18 to 45 years old. Eight healthy Egyptian volunteers who had no systemic or dermatological diseases of matching age, sex and BMI served as control. The assessment was performed according to SALT score.
Results: There was statistically highly significant difference between the two groups regarding the mean value of PGD2 in tissue in AA patients. It was significantly lower than in control group $(\mathrm{p}<0.001)$. The mean value of PGD2 in serum in AA patients was significantly lower than in control group $(\mathrm{p}<$ $0.05)$.

Conclusion: Prostaglandin D2 exhibits a strong role in etiology of alopecia areata and significantly was elevated in serum and tissue of alopecia areata patients.

Key words: Alopecia areata, prostaglandins, PG D2 Tissue \& serum.

\section{Introduction}

Alopecia areata is classified as an autoimmune disorder, characterized by one or more circumscribed, totally bald, smooth, patches appear suddenly, most often on the scalp. Alopecia areata is also called 
autoimmune alopecia. This disease affects males and females at any age. It starts in childhood in about 50\%, and before the age of 40 years in 80\% (Lattouf C et al., 2015). Alopecia Areata is inflammatory disease that involves the hair follicle and sometimes the nails. This inflammation is caused by a T- cell mediated autoimmune mechanism occurring in genetically predisposed individuals (Craiglow BG et al., 2014). The exact etiology of AA is still unclear. Autoimmune process (Zhang et al., 2015), genetic susceptibility (Petukhova et al., 2011), environmental factors (Perriconeet al., 2013), psychological stress (Willemsen et al., 2009) and oxidative stress (Abdel Fattah et al., 2011) are all suggested to contribute to the disease. The severity and onset of the disease are probably controlled by multiple factors (Alkhalifah, 2013). Furthermore, the human leukocyte antigens (HLA) have been reported to play a major role in the etiology of autoimmunity. In AA, there is an increased expression of specific HLAs in AA patients such as HLA-DR, HLA-A, HLA-B, and HLA$\mathrm{C}$ (Gilhar et al., 2007). It is histologically characterized by $\mathrm{T}$ lymphocytes around the hair follicles. These CD8 (+) NK group 2Dpositive (NKG2D (+)) $\mathrm{T}$ cells release proinflammatory cytokines and chemokines that reject the hair (Xing L et al., 2014). Besides T cells and NK cells, perifollicular mast cells were observed to contribute to the immunopathogenesis of AA, where it interacts with CD8+ T cells (Bertolini et al., 2014). The normal expression of PTGDS matched the temporal and spatial expression of hair follicle areas which were lost in the dying phase of the hair cycle. PGD2 levels peaked 7 fold higher than baseline levels immediately preceding catagen. PTGDS were expressed in the outer root sheath inferior to the bulge (Bell et al., 2003). The effect of PGD2 was tested on mouse models with inactivating mutations in each of the receptors for PGD2- PTGDR (DP-1) or GPR44 (DP-2).the result has shown that PGD2 and GPR44 inhibit hair growth; they also inhibit hair follicle regeneration after wounding (Nelson et al., 2013). Dramatic increase in inflammatory mediators is coupled with the accumulation of this lymphocytic infiltrate, where there is influx of chemokines, cytokines mainly IFN- $\gamma$, endogenous Toll-like Receptor (TLR) ligands (Alzolibani et al., 2016), as well as, changes in certain mediators such as retinoids (Duncan et al. 2013, McElwee et al., 2013 and Ito et al., 2014). These alterations were suggested to contribute to the immune privilege collapse and subsequently HF dystrophy (Ito et al., 2005). Many therapeutic options exist for AA, but none are curative or preventive (Alkhalifah, 2013). Further studies assessed prostaglandin analogues in scalp AA. In a pilot study, bimatoprost $0.03 \%$ solution was equivalent to mometasone furoate $0.1 \%$ cream, with more percentage hair regrowth, more rapid response and less side effects (Zaher et al., 2015). Prostaglandin analogs are the only 
possible treatment for hypotrichosis and alopecia of the eyelashes regardless of its etiology (Yevher et al., 2017).

\section{Subjects and Methods}

It was a prospective case-control study. The study included 45 subjects, (22 male, 15 female, 8 healthy volunteers), their ages ranged from 18 to 45 years, mean \pm SD (28.4 \pm 7.82 ). Subjects were divided into 2 groups: 37 alopecia Areata patients with progressive to stationary Alopecia Areata, 8 healthy Egyptian volunteers who had no systemic or dermatological diseases of matching age, sex and BMI served as control. We excluded Alopecia totalis and alopecia universalis, Alopecia areata solely affecting the beard, Chronic or acute, Pregnant and lactating, Patients with autoimmune diseases e.g. thyroid disease, vitiligo or SLE, Patients receiving systemic treatment relevant to alopecia areata within 3 months before enrollment into the study or topical treatment relevant to alopecia areata within 2 months before, Patients with a dermatological condition affecting the scalp other than AA: e.g. psoriasis, eczema.

Ethical consideration: Patient selection included a written consent. The study plan considering this work was accepted by the Ethical committee of Faculty of Medicine, Fayoum University, for participation in the study.

Laboratory assessment: Serum and tissue PG D2 were measured for all subjects using ELISA technique using ELISA Kit provided by Shanghai Korain Biotech CO., Ltd (Cat.No : E0989Hu). The samples were taken from areas clinically identified. Sera collected were stored at $-20{ }^{\circ} \mathrm{C}$, and tissue samples were stored at $-80 \mathrm{C}$ until analysis at Biochemistry department, Faculty of Medicine, Cairo University.

Statistical analysis was done using computer programs: Microsoft excel version 10 and Statistical Package for Social Science (SPSS) for windows version 25.0.

\section{Results}

There was a statistically significant difference between Tissue PGD2 \& Serum PGD2 in cases than control with $\mathrm{p}$ value $<0.01$. Course was progressive in 26 patients $(70 \%)$, stationary in 4 patients (10\%) and with exacerbations and remissions in 7 patients (20\%) (Fig 2). 


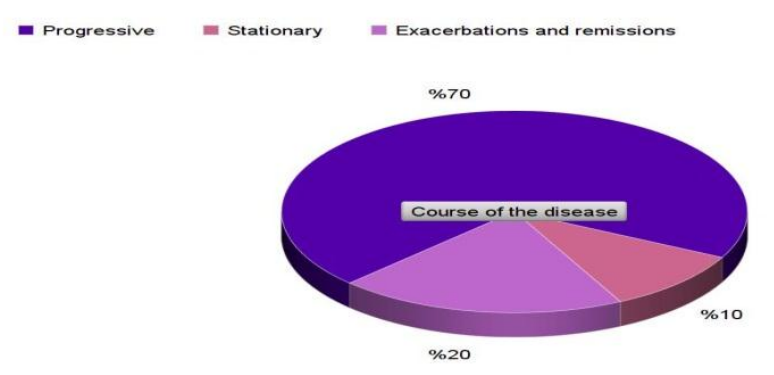

Figure 2. Course of the Disease

Five patients (13.5\%) had nail affection, all were in the form of pitting. Eleven patients (29.7\%) had a history of atopy in the form of bronchial asthma in 8 patients (20\%) and atopic dermatitis in 3 patients (7.5\%). Family history of AA was reported by 7 patients (19\%). also, 8 patients $(21.6 \%)$ reported family history of autoimmune disease including thyroid disease and type 1 diabetes mellitus (Fig 3).

\section{Figure 3. Comparison between AA patients regarding associated}

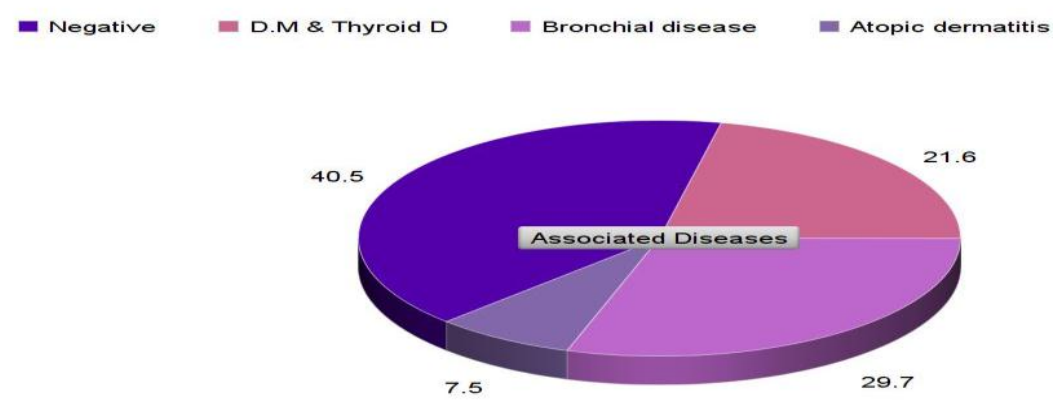

PGD2 tissue level in patients group ranged from $14.1 \mathrm{ng} / \mathrm{mg}$ to $90.3 \mathrm{ng} / \mathrm{mg}$ with a mean $\pm \mathrm{SD}$ of $45.628 \pm 18.6734 \mathrm{ng} / \mathrm{mg}$, while in the control group ranged from $17.8 \mathrm{ng} / \mathrm{mg}$ to $30.8 \mathrm{ng} / \mathrm{mg}$ with a mean \pm SD of $25.313 \pm 4.2286 \mathrm{ng} / \mathrm{mg}$. The mean value of PGD2 in tissue in AA patients was significantly lower than in control group (po < 0.001). PGD2 Serum level in patients group ranged from $82.9 \mathrm{ng} / \mathrm{L}$ to $309.5 \mathrm{ng} / \mathrm{L}$ with a mean $\pm \mathrm{SD}$ of $162.798 \pm 53.5840 \mathrm{ng} / \mathrm{L}$, while in the control group ranged from $70.7 \mathrm{ng} / \mathrm{L}$ to $166.3 \mathrm{ng} / \mathrm{L}$ with a mean $\pm \mathrm{SD}$ of $171.373 \pm 32.4471 \mathrm{ng} / \mathrm{L}$. The mean value of PGD2 in serum in AA patients was significantly lower than in control group (po < 0.05) (Table 1) (Fig 4). 
Table (1): PG D2 serum \& tissue levels

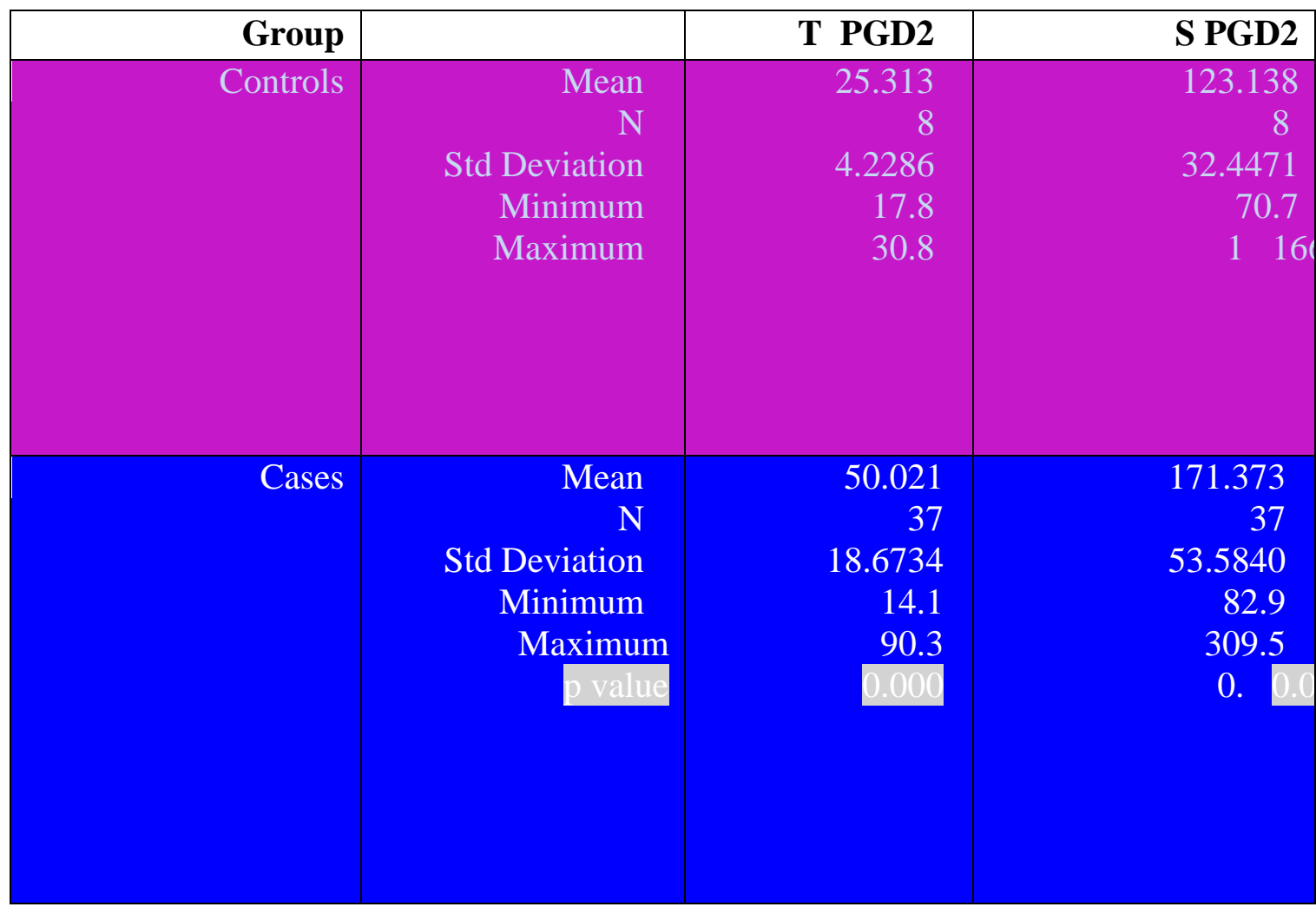

T PGD2 \& S PGD2 highly significant in cases than control

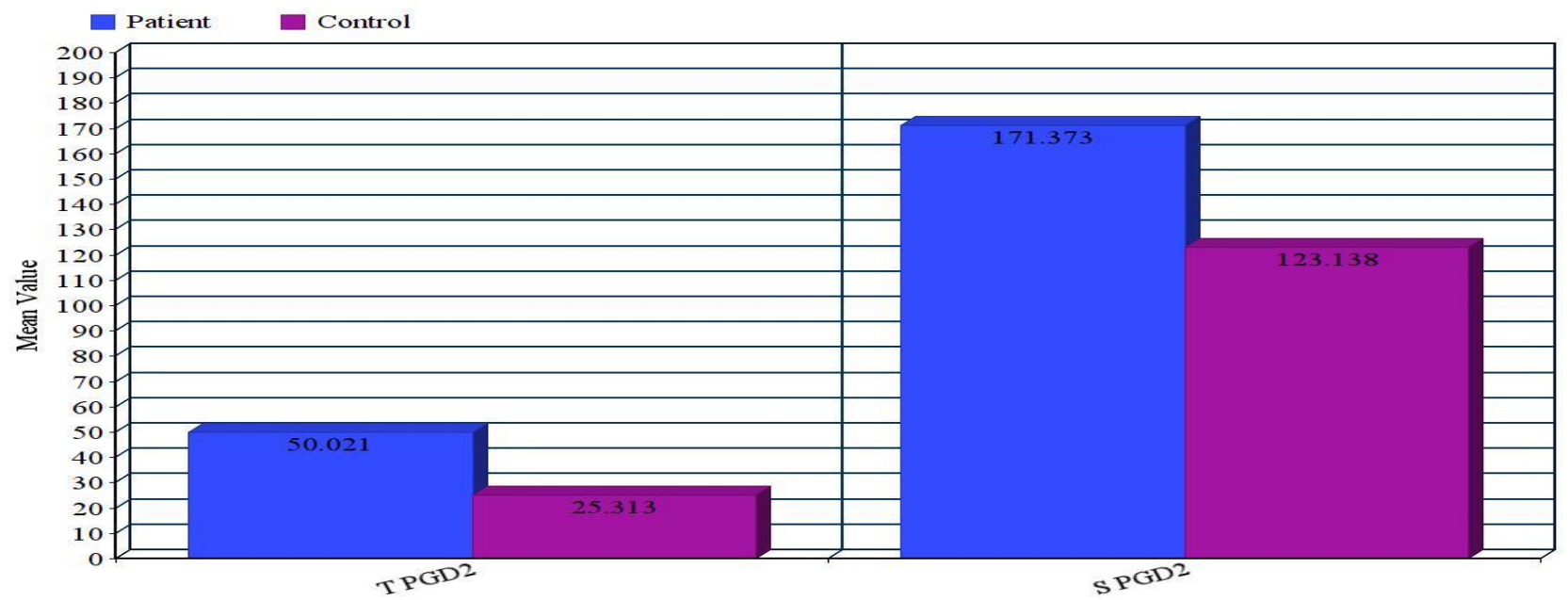

Fig.4. T PGD2 \& S PGD2 among patients \& Control groups

When correlating PGD2 with patients age, sex, onset, course, family history, duration of the disease, SALT base line and dermoscopic base line sacle were not affected by all variable factors (Table 2). 
Table 2: Correlation between PGD2 with variable factors

\begin{tabular}{|c|c|c|c|}
\hline Factors & & T PGD2 & S PGD2 \\
\hline \multirow[t]{3}{*}{ Age } & Correlation & 0.289 & -0.063 \\
\hline & & & \\
\hline & p value & 0.082 & 0.709 \\
\hline \multirow[t]{3}{*}{ Sex } & Correlation & -0.035 & -0.035 \\
\hline & & 37 & \\
\hline & $p$ value & 0.839 & 0.838 \\
\hline \multirow[t]{3}{*}{ Onset } & Correlation & 0.210 & 0.254 \\
\hline & $\mathrm{N}$ & & \\
\hline & p value & 0.211 & 0.129 \\
\hline \multirow[t]{3}{*}{ Course } & Correlation & -0.134 & -0.082 \\
\hline & $\mathrm{N}$ & 37 & 37 \\
\hline & p value & 0.429 & 0.629 \\
\hline \multirow[t]{3}{*}{ Duration } & Correlation & 0.034 & 0.257 \\
\hline & $\mathrm{N}$ & 37 & 37 \\
\hline & p value & 0.840 & 0.125 \\
\hline \multirow[t]{3}{*}{ Autoimmune } & Correlation & 0.239 & 0.294 \\
\hline & $\mathrm{N}$ & 37 & 37 \\
\hline & p value & 0.155 & 0.078 \\
\hline \multirow[t]{3}{*}{ Nail } & Correlation & -0.102 & -0.048 \\
\hline & & 37 & 37 \\
\hline & p value & 0.549 & 0.779 \\
\hline \multirow[t]{3}{*}{ Atopic } & Correlation & -0.093 & -0.166 \\
\hline & & 37 & 37 \\
\hline & p value & 0.586 & 0.325 \\
\hline \multirow[t]{3}{*}{ Family HO } & Correlation & -0.272 & 0.272 \\
\hline & & 37 & 37 \\
\hline & p value & 0.104 & 0.098 \\
\hline \multirow{3}{*}{$\begin{array}{r}\text { Family } \\
\text { Autoimmune }\end{array}$} & Correlation & 0.377 & 0.132 \\
\hline & $\mathrm{N}$ & 37 & 37 \\
\hline & p value & 0.021 & 0.436 \\
\hline \multirow[t]{3}{*}{ SALT score } & Correlation & -0.122 & -0.050 \\
\hline & & 37 & 37 \\
\hline & p value & 0.473 & 0.770 \\
\hline \multirow[t]{3}{*}{ Dermoscopic } & Correlation & 0.060 & 0.117 \\
\hline & & 37 & 37 \\
\hline & p value & 0.722 & 0.491 \\
\hline \multirow[t]{3}{*}{ Pain } & Correlation & 0.072 & -0.155 \\
\hline & & & 37 \\
\hline & $p$ value & 0.673 & 0.360 \\
\hline \multirow[t]{3}{*}{ Telengectsia } & Correlation & -0.266 & -0.071 \\
\hline & & 37 & 37 \\
\hline & $p$ value & 0.111 & 0.674 \\
\hline
\end{tabular}


There is no correlation between PG D2 levels in tissue \& serum in patients of Alopecia areata and different factors e.g. age, sex, onset, course, duration, Autoimmune association, Nail affection, atopic dermatitis, family history, family autoimmune, SALT score, dermoscopic grades, pain \& telangiectasia.

\section{Discussion}

This study is the first study that talks in particular about PG D2 in alopecia areata patients, if it has a significant role in AA as a part of the required immunity in skin comparing its levels in patients with its levels in the healthy control in both tissue and serum, There was a highly significant difference between AA patients and control group regarding PG D2 serum and tissue levels, there was a highly increase in PG D2 levels in both serum and tissue in AA patients. These results suggest that PG D2 has a strong role in Alopecia areata pathogenesis, Prostaglandin analogs are the only possible treatment for hypotrichosis and alopecia of the eyelashes regardless of its etiology (Yevher et al., 2017). Prostaglandin D2 synthase (PTGDS) is elevated at the mRNA and protein levels in bald scalp compared to haired scalp of men with AGA. The product of PTGDS enzyme activity, prostaglandin D2 (PGD2), is similarly elevated in bald scalp. During normal follicle cycling in mice, PTGDs and PGD2 levels increase immediately preceding the regression phase, suggesting an inhibitory effect on hair growth. PGD2 inhibits hair growth in explanted human hair follicles and when applied topically to mice. Hair growth inhibition requires the PGD2 receptor $G$ protein (heterotrimeric guanine nucleotide) coupled receptor 44(GPR44), but not the PGD2 receptor 1 (PTGDR). Furthermore, we find that a transgenic mouse,K14- PTGs2, which targets prostaglandin- endoperoxide synthase 2 expression to the skin (Garza et al., 2012). It was one of the most abundant transcripts in bald scalp compared to haired scalp. PTGDS is a prostaglandin synthase enzyme which acts downstream of the cyclooxgygenase enzymes (Goodman et al., 1996). PTGDS was confirmed to be elevated in bald scalp by mRNA, protein and also its enzymatic product, PGD2. Importantly, its increase was confirmed by mass spectrometry which has been shown to be superior to conventional ELISA based methods which use marginally specific antibodies for the selective identification of individual prostaglandin species (Bell et al., 2003). So confirmed the correlation between PGD2 and alopecia.

There was a highly statistically significant difference between between AA patients and control group regarding PG D2 serum and tissue levels, there was a highly 
increase in PG D2 levels in both serum and tissue in AA patients with $\mathrm{p}$ value $<0.01$. These results suggest that PG D2 has a strong role in Alopecia areata pathogenesis. This is the first study to prove the relation between PG D2 and Alopecia areata

\section{Conclusion and recommendations}

Prostaglandin D2 exhibits a strong role in AA with its inflammatory effect. It was highly expressed in Alopecia areata patients serum\& tissue levels than healthy individuals. We suggest that prostaglandin analogue could become a potential therapeutic target for treating AA in the future with its strong role in Alopecia areata, and we need further clinical study to asses which prostaglandin analogues will be highly curable with alopecia areata.

\section{Acknowledgment}

I am greatly thankful to Dr|Talal

\begin{abstract}
Ahmed Abdel-Raheem, Professor of
\end{abstract} Dermatology, STDS and Andrology, Fayoum University, for the precious advices and great help. I am deeply grateful to my principal supervisors DrlSamar Mohamed Ragai ElTahlawi, Professor of Dermatology, Faculty of Medicine-Cairo University, for giving me the privilege of being under her supervision in this study, I am very grateful to Prof. Dr. Olfat Gamil Shakir, Professor of Medical Biochemistry, Cairo University, for her help and her valuable supervision throughout the practical part of this work, and to DrlMohamed Hassan Mohamed, Lecturer of Dermatology STDS and Andrology, Fayoum University, for his precious advices and great help during the preparation of this work. I was blessed to get their support.

\section{References}

- Lattouf C, Jimenez JJ, Tosti A, Miteva M, Wikramanayake TC (2015) : Treatment of alopecia areata with simvastatin/ezetimibe. J Am Acad Dermatol 359-361.

- Craiglow BG and King BA (2014): oral tofacitinib reverses alopecia universalis in a patient with plaque psoriasis. J Invest Dermatol 2988-2990.

- Petukhova L, Cabral RM, Mackay J, Clynes R, Christiano AM (2011): The genetics of alopecia areata: what's new and how will it help our patients? .Dermatol Ther. 24(3):326-36.

- Perricone C, Colafrancesco S, Mazor RD, Soriano A, Agmon-Levin N, Shoenfeld Y (2013): Autoimmune/inflammatory syndrome induced by adjuvants (ASIA) Unveiling the pathogenic, clinical and diagnostic aspects. J Autoimmun.;47:1-16.

- $\quad$ Zhang X, Zhao Y, Ye Y, Li S, Qi S, Yang Y, Cao H, Yang J, Zhang $X$ (2015): Lesional infiltration of mast cells, Langerhans cells, $\mathrm{T}$ cell and local cytokine profiles inalopecia areata. Arch Dermatol Res.;307(4):319-31.

- Willemsen R, Vanderlinden J, Roseeuw D, Haentjens P (2009): Increased history of childhood and lifetime traumatic events among adults with alopecia areata. J Am Acad Dermatol: 60(3): 388-93. 
- Abdel Fattah NS, Ebrahim AA and El Okda ES (2011): $\quad$ Lipid peroxidation/antioxidant activity in patients with alopecia areata. J Eur Acad Dermatol Venereol.;25(4):403-8.

- Alkhalifah A. (2013): Alopecia areata update, Dermatol Clin.; 31(1):93-108.

- Gilhar A, Paus R and Kalish RS (2007): Lymphocytes, neuropeptides, and genes involved in alopecia areata. J Clin Invest.;117(8):2019-27.

- Bertolini M, Zilio F, Rossi A, Kleditzsch P, Emelianov VE, Gilhar A, Keren A, Meyer KC, Wang E, Funk W, McElwee K, Paus R (2014): Abnormal interactions between perifollicular mast cells and CD8+ T-cells may contribute to the pathogenesis of alopecia areata. PLoS One.;9(5):e94260.

- Bell LC, Ide T, Lawson JA, McNamara P, Reilly M, FitzGerald GA (2003): Biosynthesis of 15-deoxy-delta12,14-PGJ2 and the ligation of PPARgamma. J Clin Invest.;112(6):945-55.

- Nelson AM, Loy DE, Lawson JA, Katseff AS, Fitzgerald GA, Garza LA (2013): Prostaglandin D2 Inhibits Wound-Induced Hair Follicle Neogenesis through the Receptor, Gpr44. J Invest Dermatol.;133(4):881-9.

- Alzolibani AA, Rasheed Z, Bin Saif G MS, Al-Dhubaibi MS, Al Robaee AA (2016): Altered expression of intracellular Toll-like receptors in peripheral blood mononuclear cells from patients with alopecia areata. BBA Clin.;5:134-42.

- Duncan FJ, Silva KA, Johnson CJ, King BL, Szatkiewicz JP, Kamdar SP, Ong DE, Napoli JL, Wang J, King LE Jr, Whiting
DA, McElwee KJ, Sundberg JP, Everts HB (2013): Endogenous retinoids in the pathogenesis of alopecia areata. J Invest Dermatol.;133(2):334-43.

- McElwee KJ, Gilhar A, Tobin DJ, Ramot Y, Sundberg JP, Nakamura M, Bertolini M, Inui S, Tokura Y, King LE Jr, DuqueEstrada B, Tosti A, Keren A, Itami S, Shoenfeld Y, Zlotogorski A, Paus R (2013): What causes alopecia areata? Exp Dermatol.;22(9):609-26.

- Ito T and Tokura Y (2014): The role of cytokines and chemokines in the T-cellmediated auto- immune process in alopecia areata. Exp Dermatol.;23(11):787-91.

- Ito T, Ito N, Saathoff M, Bettermann A, Takigawa M, Paus R (2005): Interferongamma is a potent inducer of catagen-like changes in cultured human anagen hair follicles. Br J Dermatol. (4):623-31.

- Zaher H, Gawdat HI, Hegazy RA, Hassan M (2015): Bimatoprost versus Mometasone Furoate in the Treatment of Scalp Alopecia Areata: A Pilot Study. Dermatology.;230(4):308-13.

- Yevher L and Antonella T (2017): Bimatoprost for the treatment of eyelash, eyebrow and scalp alopecia ,Expert Opinion on Investigational Drugs .;(26):515-522.

- Garza LA, Liu Y, Yang Z, Alagesan B, Lawson J, Norberg S, Loy D, Zhao T, Blatt H, Stanton D, Carrasco L, Ahluwalia G, Fischer S, FitzGerald G, Cotsarelis G (2012): Prostaglandin D2 inhibits hair growth and is elevated in bald scalp of men with androgenetic alopecia.,Sci Transl ;4(126): 10.1126.

- Goodman LS, Gilman A, Hardman JG (1996): Goodman \& Gilman's the pharmacological basis of therapeutics. 9 . Xxi. New York: McGraw-Hill, Health Professions Division. p. 1905. 